\title{
To operate or not to operate on women with deep infiltrating endometriosis (DIE) before in vitro fertilization (IVF)
}

\author{
Márcia Mendonça Carneiro ${ }^{1,2,3,4}$, Luciana Maria Pyramo Costa ${ }^{1,4}$, Ivete de Ávila ${ }^{2,4}$ \\ ${ }^{1}$ Endometriosis Multidisciplinary Team, Mater Dei Hospital, Belo Horizonte, MG, Brazil \\ ${ }^{2}$ Human Reproduction Center at Mater Dei Hospital, Belo Horizonte, MG, Brazil \\ ${ }^{3}$ Department of Obstetrics and Gynecology, Federal University of Minas Gerais, Brazil \\ ${ }^{4}$ Endometriosis Multidisciplinary Team, Biocori Hospital, Belo Horizonte, MG, Brazil
}

\begin{abstract}
Deep infiltrating endometriosis (DIE) can cause infertility and pelvic pain. There is little evidence of a clear connection between DIE and infertility, and the absolute benefits of surgery for DIE have not been established. This paper aimed to review the current literature on the effect of surgery for DIE on fertility, pregnancy, and IVF outcomes. Clinicians should bear in mind that a comprehensive clinical history is useful to identify patients at risk for endometriosis, although many women remain asymptomatic. Imaging can be useful to plan surgery. The effect of surgery on the fertility of women with DIE remains unanswered due to the heterogeneous nature of the disease and the lack of trials with enough statistical power and adequate followup. Surgery is not recommended when the main goal is to treat infertility or to improve IVF results. Decisions should be tailored according to the individual needs of each woman. Patients must be provided information on the potential benefits, harm, and costs of each treatment alternative, while the medical team observes factors such as presence of pelvic pain, patient age, lesion location, and previous treatments. In this scenario, management by a multidisciplinary endometriosis team is a key step to achieving successful outcomes.
\end{abstract}

Keywords: deep infiltrating endometriosis, in vitro fertilization, surgical treatment, infertility

\section{INTRODUCTION}

Endometriosis is a benign gynecological disorder characterized by the presence and growth of endometriumlike tissue in sites outside the uterine cavity, primarily on the pelvic peritoneum and ovaries (Giudice \& Kao, 2004; Bulun, 2009). It affects $5-10 \%$ of women of reproductive age and the main clinical features are chronic pelvic pain and infertility (Gupta et al., 2008; de Ziegler et al., 2010; Carneiro et al., 2010).

Endometriosis seemingly causes infertility by interfering with fundamental steps in the reproductive process. The mechanisms of infertility associated with endometriosis remain controversial. Current evidence suggests that endometriosis adversely affects ovarian and tubal function as well as uterine receptivity resulting in female infertility. Endometriosis may also distort pelvic anatomy and produce large ovarian masses (Gupta et al., 2008; de Ziegler et al., 2010; Burney \& Giudice, 2012). It is not clear, however, whether the products of endometriosis are a cause of infertility or a para-phenomenon.

Apparently, there are three types of endometriosis: superficial endometriosis, ovarian endometrioma, and deeply infiltrating endometriosis (DIE) (Tosti et al., 2015). DIE is considered a specific entity which has been arbitrarily defined in histological terms as endometriotic lesions extending more than $5 \mathrm{~mm}$ underneath the peritoneum (Cornillie et al., 1990; Koninckx et al., 1991). DIE is responsible for painful symptoms, whose severity has been strongly correlated with the anatomical location of the DIE lesions (Ávila et al., 2016).

Present treatment options of endometriosis-associated infertility include surgery, superovulation with intrauterine insemination, and in vitro fertilization (IVF) (de Ziegler et al., 2010; American Society for Reproductive Medicine (ASRM), 2012; Johnson \& Hummelshoj, 2013). Although many questions remain unanswered, there is evidence to support the use of laparoscopic surgery to improve fertility. (Vercellini et al., 2009; Berlanda et al., 2013).

In addition, some studies suggest that the presence of endometriosis per se may adversely affect pregnancy and neonatal outcomes (Brosens et al., 2012; Vigano et al., 2015; Jacques et al., 2016), while a recent systematic review stated that complications of endometriosis during pregnancy were rare and there was no evidence that the disease had a major detrimental effect on pregnancy outcomes (Leone Roberti Maggiore et al., 2016). Women with incomplete surgical removal of posterior DIE may nevertheless present with a higher of risk complications during pregnancy and delivery. (Exacoustos et al., 2016).

The role of surgical treatment in infertile women with endometriosis remains elusive (Vercellini et al., 2009; Douay-Hauser et al., 2011; Berlanda et al., 2013). With the exception of peritoneal disease, randomized trials have not looked into the effects of surgery in subfertile women with endometriosis (Dufy et al., 2014). Therefore, it has not been possible to define the absolute benefit of surgery for ovarian and rectovaginal lesions (Vercellini et al., 2012; Berlanda et al., 2013). The dilemma remains when we are faced with an infertile woman suffering from DIE: should they be offered first-line IVF treatment or surgery?

\section{METHODS}

This paper aimed to review the current literature on the effect of surgery for DIE on fertility and IVF outcomes. A search was carried out on the Cochrane Library (July 2016) and PUBMED (1966 to July 2016) for relevant papers written in English, Italian, Spanish or French, which were the languages the authors could read. Combinations of medical subject heading terms including "deep infiltrating endometriosis and assisted reproductive technologies," "deep infiltrating endometriosis and infertility," "in vitro fertilization," "pregnancy," "intestinal endometriosis," and " urinary endometriosis" were used. The authors also looked for systematic reviews and Guidelines from the European Society of Human Reproduction and Embryology (ESHRE) and the American Society for Reproductive Medicine (ASRM), and books. The purpose was to find evidence to answer the following clinical questions: how should DIE be diagnosed in infertile women? How might DIE affect fertility and pregnancy? What are the possible benefits of surgery for DIE before IVF? 


\section{RESULTS AND DISCUSSION}

The search yielded 1,206 papers. The authors read the abstracts and excluded irrelevant papers and repeated titles appearing in more than one of the search combinations used. The full-text papers in the resulting list were obtained and read. The final list of relevant publications contained 60 papers.

How should DIE be diagnosed in infertile women?

Comprehensive clinical history is useful to identify patients at risk for endometriosis, although establishing the diagnosis of the disease based solely on risk factors may be misleading, as a large portion of women with endometriosis remain completely asymptomatic (Ballard et al., 2010; Carneiro et al., 2013).

Finding women at risk may help identify the individuals who might benefit from diagnostic laparoscopy. Clinical history and symptom reports alone cannot be relied on to screen women with chronic pelvic pain. Preoperative questionnaires exploring four clinical symptoms of women with DIE associated with endometriomas may help identify high-risk groups (Lafay Pillet et al., 2014). Individuals categorized in these groups should be referred to specialized centers for thorough assessment (Carneiro et al., 2013; Dunselman et al., 2014). Early diagnosis of DIE reduces care costs and allows the use of effective medical and surgical treatments to manage symptoms and improve the long-term outcome for patients. DIE should be considered as a diagnostic possibility in women with painful nodules/ pain in areas of the rectovaginal wall or with visible nodules in the posterior vaginal fornix (Dunselman et al., 2014).

Ultrasound has only recently been introduced in the diagnosis of DIE. Several studies provide enough evidence to show that transvaginal ultrasound (TVUS) is not only useful, but a strategic tool in the preoperative mapping of lesions and in surgery planning (Ferreira \& Carneiro, 2010; Dunselman et al., 2014; Exacoustos et al., 2016).

As it is a noninvasive, readily available test in most centers, TVUS plays a pivotal role in the assessment of women with endometriosis along with bimanual pelvic examination. (Abrão et al., 2007; Hudelist et al., 2011;). Studies revealed that TVUS, when performed by skilled professionals, clearly enhances diagnostic accuracy, especially in patients with ovarian endometriomas or DIE involving the uterosacral ligaments, bladder or rectosigmoid junction; TVUS appears to be equally efficient in cases of DIE affecting the vagina and the pouch of Douglas (Hudelist et al., 2011; Guerriero et al., 2015; Reid \& Condous, 2017).

Nisenblat et al. (2016) published a Cochrane Review in an attempt to establish the role of imaging in the diagnosis of endometriosis. The authors looked into 49 studies: ten involving endometriomas, 15 on DIE, and 33 looking at endometriosis at specific anatomical sites. Unfortunately, the majority of the studies were of poor methodological quality and none of the imaging methods studied was able to replace surgery in the diagnosis of endometriosis. The ESHRE 2014 Endometriosis Guidelines states that imaging may help define the extent of involvement in women with DIE. In addition to detecting endometriomas, magnetic resonance imaging (MRI) is an option when rectosigmoid endometriosis is considered.

Clinical practice still lacks accurate noninvasive diagnostic tests for endometriosis. A recent Cochrane review (Nisenblat et al., 2016) evaluated possible noninvasive imaging tests and biomarkers for the diagnosis of endometriosis, but the authors were unable to find clinically useful biomarkers, and the evidence available was either insufficient or of poor-quality. Therefore, laparoscopy is still the gold standard for the diagnosis of endometriosis and the use of noninvasive tests either alone or in combination should only be considered in research settings.

Clinicians should therefore bear in mind that comprehensive clinical history is useful to find patients at risk for endometriosis, although establishing the diagnosis of the disease based solely on risk factors might be misleading, as a significant portion of women with endometriosis remain completely asymptomatic (Carneiro et al., 2013).

Despite its low sensitivity and specificity, vaginal examination and evaluation of specific symptoms should not be completely ruled out in the basic diagnosis of endometriosis or in the planning of further therapeutic interventions (Carneiro et al., 2013; Ávila et al., 2016).

TVUS is a reproducible method used in the assessment of pelvic endometriosis severity that offers good agreement with laparoscopy findings. Other imaging techniques such as MRI are suitable for the diagnosis of endometriosis, but it is our belief that TVUS is the preferred initial imaging mode, since it is readily available in most centers and offers an easy access, affordable and accurate means of diagnosing patients with ovarian endometriomas and DIE (Benacerraf \& Groszmann, 2012; Dunselman et al., 2014).

The decision to perform surgery for deep endometriosis is mainly clinical. TVUS and other imaging techniques such as MRI may be useful in the preoperative estimation of lesion size and lateral extension, and play a vital role in surgical planning and choice of approach. It remains unclear, however, the extent to which preoperative ultrasonography or MRI should influence the decision to perform surgery, or the choice of procedure to treat deep endometriosis (Carneiro et al., 2013).

\section{How might DIE affect fertility and pregnancy?}

Although DIE has been frequently associated with infertility, there is little evidence connecting the disease and infertility. Studies suggest that infertility in women with DIE is probably related to the strong link between DIE and adhesions, superficial endometriotic implants, ovarian endometriomas, and adenomyosis (Somigliana \& GarciaVelasco, 2015).

Several anomalies are thought to contribute to DIErelated infertility: hormonal function (estrogen and progesterone receptors) and immunological factors, such as peritoneal macrophages, natural killer cells, and lymphocytes (Gupta et al., 2008; de Ziegler et al., 2010; Burney \& Giudice, 2012).

Unfortunately, the relationship between DIE and infertility is rather complex and a final conclusion on the matter yet to be produced (Somigliana \& Garcia-Velasco, 2015). When considering infertility in women with DIE, clinicians must bear in mind a variety of confounding factors that might interfere with the interpretation of studies. Firstly, other types of endometriosis, such as peritoneal and ovarian, may accompany DIE and affect fertility on their own (de Ziegler et al., 2010). Isolated DIE is rarely encountered, whereas associations with other forms of endometriosis are frequently seen (Somigliana et al., 2004). Secondly, superficial peritoneal lesions may produce inflammatory cytokines and chemokines, and thus produce, in an altered hormonal milieu, increased oxidative stress and impaired sperm and tubal function (Gupta et al., 2008; de Ziegler et al., 2010). In addition, endometriomas may interfere with folliculogenesis and result in poor oocyte and embryo quality and impair ovarian response and pregnancy rates in IVF (Ballester et al., 2012; Yang et al., 2015). Adenomyosis, a finding more frequent in women with DIE than other forms of endometriosis, might also significantly reduce $(68 \%)$ the likelihood of pregnancy in women attempting conception after surgery 
for rectovaginal or colorectal endometriosis ( $\mathrm{Di}$ Donato et al., 2014; Vercellini et al., 2014). And last but not least, published data suggests the endometrium itself harbors several anomalies in women with endometriosis, which result in reduced endometrial receptivity and decreased implantation rates (Gupta et al., 2008; de Ziegler et al., 2010).

\section{What is the impact of surgery on the fertility of women with DIE?}

DIE is a rather heterogeneous disease. Analysis of the anatomical location of the lesions revealed a multifocal pattern, as $61 \%$ of the women with DIE had more than one site simultaneously affected (Ávila et al., 2016). The multifocal distribution pattern observed in women with DIE makes it more difficult to study possible relationships between pain and anatomical location, or to establish its role on fertility (Ávila et al., 2016). Besides, there is a paucity of data from randomized controlled trials, as the available published studies are case series or uncontrolled studies with many confounding factors such as use of ART and presence of other infertility factors.

Natural fecundity in women with endometriosis is rarely evaluated, and except for peritoneal disease, no randomized trials have been carried out to assess the effect of surgery in this setting (Somigliana \& GarciaVelasco, 2015).

Brown \& Farquhar (2014) compiled evidence from 17 Cochrane Systematic Reviews on treatment options for women with pain or subfertility associated with endometriosis using live birth, clinical pregnancy, ongoing pregnancy, miscarriage and adverse events as primary outcomes. Seven reviews concerned infertility: two presented ART-related outcomes (Sallam et al., 2006 and Benschop et al., 2010), while the remaining described spontaneous pregnancy. Post-surgical medical treatment resulted in no benefits in terms of pregnancy rates, but three months of treatment with GnRH agonists improved pregnancy rates in women with endometriosis undergoing IVF. Excisional surgery resulted in better spontaneous pregnancy rates in the 9-12 month period after surgery when compared to ablative surgery. Laparoscopic surgery improved live birth and pregnancy rates when compared to diagnostic laparoscopy alone. Medical treatment apparently did not improve clinical pregnancy rates.

Duffy et al. (2014) found that laparoscopic surgery was associated with an increased live birth or ongoing pregnancy and clinical pregnancy rates in comparison to diagnostic laparoscopy. No solid conclusions of safety were drawn, as there was insufficient evidence on adverse events.

The two randomized controlled trials reported by Hart et al. (2008) suggested a benefit of excisional surgery over drainage or ablation of endometriomata to achieve pregnancy. Benschop et al. (2010) evaluated surgical interventions for endometrioma before IVF. The authors did not find evidence of a difference in clinical pregnancy rates between surgery (aspiration or cystectomy) for endometrioma prior to ART and expectant management.

While some advocate complete surgical removal of endometriotic lesions to improve fertility (Daraï et al., 2005; Ferrero et al., 2009), others affirm that extensive surgery for peritoneal endometriosis and DIE in infertile women does not improve global fertility prognosis and may be associated with higher complication rates (Vercellini et al., 2006; Douay-Hauser et al., 2011; Vercellini et al., 2012). Vercellini et al. (2012) pinpointed in their literature review that women should be carefully counseled on the real chances of getting pregnant after surgery. The authors found that pregnancy rates decreased by $15 \%$ in individuals who sought spontaneous conception after surgery versus women offered IVF (39\% vs. 24\%). Apparently, time to conception after surgery is also a matter to consider, as delays have been associated with lower pregnancy and higher relapse rates (Somigliana et al., 2010).

In short, the effect of surgery on the fertility of women with DIE remains unanswered due to the heterogeneous nature of the disease and the lack of adequate trials with enough power and follow-up to study the matter. Surgery cannot be recommended when the main goal is to treat infertility, as the evidence to support such approach is still scant. Decisions should be tailored according to the individual needs of each woman after they are provided with information on the potential benefits, harm, and costs of each treatment alternative (Vercellini, 2015).

\section{What are the possible benefits of surgery for DIE before IVF?}

According to the guidelines of the European Society of Human Reproduction and Embryology (ESHRE) (Dunselman et al., 2014), there is limited evidence for performing surgery with the sole objective of increasing live birth rates. IVF is recommended in cases of infertility associated with endometriosis, if pelvic anatomy is distorted and tubal function impaired, or in cases of male factor infertility and/ or other treatments have failed. The main purpose of surgery for women suffering from endometriosis-related infertility ideally revolves around the restoration of normal pelvic anatomical relationships and preservation of the function of pelvic organs.

Bianchi et al. (2009) published the only prospective study available to date. The authors aimed at comparing IVF results in women with DIE-associated infertility submitted to extensive laparoscopic excision of endometriosis before IVF to subjects not operated on before IVF. This prospective cohort study included 179 women divided into two groups: IVF only $(n=105)$ and surgical resection of DIE lesions before IVF $(n=64)$. The odds of achieving pregnancy were 2.45 times higher in the group submitted to surgical excision before IVF.

DIE has been blamed for lowering the pregnancy rates of IVF cycles. Ballester et al. (2012) carried out a retrospective study and looked at 103 women with endometriomas ( $\mathrm{n}$ $=30$ ) and with endometriomas associated with DIE ( $n=$ 73). When associated with endometrioma, DIE adversely affected cumulative pregnancy rates $(82.5 \%$ vs. $69.4 \%)$. The authors recommended surgery when pregnancy was not achieved after three attempts at IVF. Centini et al. (2016) also reported that the surgical removal of multiple lesions increased pregnancy and live birth rates both spontaneously and after IVF. On the other hand, Capelle et al. (2015) considered that surgery for DIE before IVF did not result in improved pregnancy and birth rates. Interestingly, infertile women with DIE trying to have a second child and who had had surgery had high live birth rates $(78 \%)$ and a spontaneous pregnancy rate of $54 \%$ (Boujenah et al., 2016).

The impact of surgery on IVF results remains controversial. While women with advanced-stage endometriosis submitted to surgery before IVF did not respond as well to gonadotropins when compared to women with tubal-factor infertility, the implantation, pregnancy, and delivery rates were nonetheless similar (Matalliotakis et al., 2007). Complete elimination of all visible endometriotic lesions in women with minimal and mild endometriosis undergoing IVF may result in shorter time to pregnancy and higher live birth rates (Opøien et al., 2011). Other authors have suggested that IVF pregnancy rates of women with DIE may be significantly improved after extensive laparoscopic excision of DIE (Bianchi et al., 2009). A combination of surgery with IVF has been suggested as a more effective approach in 
endometriosis-associated infertility (Coccia et al., 2008; Barri et al., 2010; Ballester et al., 2012; Capelle et al., 2015). With the exception of patients with endometrioma, infertile women with various stages of endometriosis have enjoyed the same success rates with IVF as patients with tubal factor infertility (Opøien et al., 2011).

The effect of surgery in this setting remains controversial. The available published studies are observational and are not large enough to allow for any definitive conclusions. Except for peritoneal disease, no randomized trials have been published to determine the effect of surgery in subfertile women with endometriosis (Brown \& Farquhar, 2014). It remains therefore impossible to define the absolute benefit of surgery for ovarian and rectovaginal lesions. The decision to undergo surgery for endometriosis-associated subfertility must be thoroughly debated with the patient. Detailed information weighing risks and benefits, and other variables such as presence of pain, large or complex adnexal masses, bowel or ureteral stenosis, and coexisting infertility factors, must be discussed. Specifically in cases of recurrent endometriosis, IVF should generally be the first option (Vercellini et al., 2012; ASRM, 2012; Berlanda et al., 2013).

\section{CONCLUSION}

The role of surgery in the treatment of infertile women with DIE remains a matter of intense debate. Available evidence is poor, as it amounts mostly from case series, which may bias possible conclusions. Therefore, a clearcut conclusion cannot be drawn. Women with DIE should be counseled individually taking into consideration several factors such as presence of pelvic pain and other symptoms, age, lesion location, previous treatments (surgery and ART), as well as possible pregnancy complications. In this scenario, management by a multidisciplinary endometriosis team is a key factor in achieving successful outcomes.

\section{CONFLICT OF INTEREST}

The authors have no conflicts of interest to report.

\section{Corresponding author:}

Márcia Mendonça Carneiro

Department of Obstetrics and Gynecology,

Federal University of Minas Gerais,

Belo Horizonte, MG, Brazil

E-mail: marciamc.ufmg@gmail.com

\section{REFERENCES}

Abrão MS, Gonçalves MO, Dias JA Jr, Podgaec S, Chamie LP, Blasbalg R. Comparison between clinical examination, transvaginal sonography and magnetic resonance imaging for the diagnosis of deep endometriosis. Hum Reprod. 2007;22:3092-7. PMID: 17947378 DOI: $10.1093 /$ humrep/dem 187

Ávila I, Filogônio IDS, Costa LMP, Carneiro MM. Anatomic distribution of deep infiltrating endometriosis and its relationship to pelvic pain. J Gynecol Surg. 2016,32:99103. DOI: $10.1089 /$ gyn.2015.0092

Ballard K, Lane H, Hudelist G, Banerjee S, Wright J. Can specific pain symptoms help in the diagnosis of endometriosis? A cohort study of women with chronic pelvic pain. Fertil Steril. 2010;94:20-7. PMID: 19342028 DOI: $10.1016 /$ j.fertnstert.2009.01.164
Ballester M, Oppenheimer A, Mathieu d'Argent E, Touboul $C$, Antoine JM, Nisolle $M$, Daraï $E$. Deep infiltrating endometriosis is a determinant factor of cumulative pregnancy rate after intracytoplasmic sperm injection/in vitro fertilization cycles in patients with endometriomas. Fertil Steril. 2012;97:367-72. PMID: 22177465 DOI: $10.1016 /$ j.fertnstert.2011.11.022

Barri PN, Coroleu B, Tur R, Barri-Soldevila PN, Rodríguez I. Endometriosis-associated infertility: surgery and IVF, a comprehensive therapeutic approach. Reprod Biomed Online. 2010;21:179-85. PMID: 20541976 DOI: $10.1016 /$ j.rbmo.2010.04.026

Benacerraf BR, Groszmann Y. Sonography should be the first imaging examination done to evaluate patients with suspected endometriosis. J Ultrasound Med. 2012;31:6513. PMID: 22441923 DOI: 10.7863/jum.2012.31.4.651

Benschop L, Farquhar C, van der Poel N, Heineman MJ. Interventions for women with endometrioma prior to assisted reproductive technology. Cochrane Database Syst Rev. 2010;(11):CD008571. PMID: 21069706 DOI: 10.1002/14651858.CD008571.pub2

Berlanda N, Vercellini P, Somigliana E, Frattaruolo MP, Buggio L, Gattei U. Role of surgery in endometriosisassociated subfertility. Semin Reprod Med. 2013;31:13343. PMID: 23446860 DOI: $10.1055 / s-0032-1333478$

Bianchi PH, Pereira RM, Zanatta A, Alegretti JR, Motta EL, Serafini PC. Extensive excision of deep infiltrative endometriosis before in vitro fertilization significantly improves pregnancy rates. J Minim Invasive Gynecol. 2009;16:174-80. PMID: 19249705 DOI: $10.1016 /$ j.jmig.2008.12.009

Boujenah J, Hugues JN, Sifer C, Cedrin-Durnerin I, Bricou A, Poncelet $C$. Second live birth after undergoing assisted reproductive technology in women operated on for endometriosis. Fertil Steril. 2016;105:129-33. PMID: 26493118 DOI: $10.1016 /$ j.fertnstert.2015.09.039

Brosens I, Brosens JJ, Fusi L, Al-Sabbagh M, Kuroda $\mathrm{K}$, Benagiano G. Risks of adverse pregnancy outcome in endometriosis. Fertil Steril. 2012;98:30-5. PMID: 22386841 DOI: $10.1016 /$ j.fertnstert.2012.02.024

Brown J, Farquhar C. Endometriosis: an overview of Cochrane Reviews. Cochrane Database Syst Rev. 2014;(3):CD009590. PMID: 24610050 DOI: 10.1002/14651858.CD009590.pub2

Bulun SE. Endometriosis. N Engl J Med. 2009;360:268-79. PMID: 19144942 DOI: $10.1056 /$ NEJMra0804690

Burney RO, Giudice LC. Pathogenesis and pathophysiology of endometriosis. Fertil Steril. 2012;98:511-9. PMID: 22819144 DOI: $10.1016 /$ j.fertnstert.2012.06.029

Capelle A, Lepage J, Langlois C, Lefebvre C, Dewailly $D$, Collinet $P$, Rubod C. Surgery for deep infiltrating endometriosis before in vitro fertilization: no benefit for fertility? Gynecol Obstet Fertil. 2015;43:109-16. PMID: 25595945 DOI: $10.1016 /$ j.gyobfe.2014.12.003 
Carneiro MM, Filogônio ID, Costa LMP, de Ávila I, Ferreira MC. Accuracy of clinical signs and symptoms in the diagnosis of endometriosis. J Endometr Pelvic Pain Disord. 2010;2:63-70.

Carneiro MM, Filogônio ID, Costa LM, de Ávila I, Ferreira MC. Clinical prediction of deeply infiltrating endometriosis before surgery: is it feasible? A review of the literature. Biomed Res Int. 2013;2013:564153. PMID: 24089684 DOI: $10.1155 / 2013 / 564153$

Centini G, Afors K, Murtada R, Argay IM, Lazzeri L, Akladios CY, Zupi E, Petraglia F, Wattiez A. Impact of laparoscopic surgical management of deep endometriosis on pregnancy rate. J Minim Invasive Gynecol. 2016;23:113-9. PMID: 26427703 DOI: $10.1016 / j . j m i g .2015 .09 .015$

Coccia ME, Rizzello F, Cammilli F, Bracco GL, Scarselli G. Endometriosis and infertility Surgery and ART: An integrated approach for successful management. Eur ] Obstet Gynecol Reprod Biol. 2008;138:54-9. PMID: 18243485 DOI: 10.1016/j.ejogrb.2007.11.010

Cornillie FJ, Oosterlynck D, Lauweryns JM, Koninckx PR. Deeply infiltrating pelvic endometriosis: histology and clinical significance. Fertil Steril. 1990;53:978-83. PMID: 2140994

Daraï E, Marpeau O, Thomassin I, Dubernard G, Barranger $E$, Bazot $M$. Fertility after laparoscopic colorectal resection for endometriosis: preliminary results. Fertil Steril. 2005;84:945-50. PMID: 16213848 DOI: $10.1016 /$ j.fertnstert.2005.04.037

de Ziegler D, Borghese B, Chapron C. Endometriosis and infertility: pathophysiology and management. Lancet. 2010;376:730-8. PMID: 20801404 DOI: $10.1016 / S 0140-6736(10) 60490-4$

Di Donato N, Montanari G, Benfenati A, Leonardi $D$, Bertoldo V, Monti G, Raimondo D, Seracchioli R. Prevalence of adenomyosis in women undergoing surgery for endometriosis. Eur J Obstet Gynecol Reprod Biol. 2014;181:289-93. PMID: 25201608 DOI: $10.1016 /$ j.ejogrb.2014.08.016

Douay-Hauser N, Yazbeck C, Walker F, Luton D, Madelenat $P$, Koskas $M$. Infertile women with deep and intraperitoneal endometriosis: comparison of fertility outcome according to the extent of surgery. J Minim Invasive Gynecol. 2011;18:622-8. PMID: 21802376 DOI: $10.1016 /$ j.jmig.2011.06.004

Duffy JMN, Arambage K, Correa FJ, Olive D, Farquhar C, Garry R, Barlow DH, Jacobson TZ. Laparoscopic surgery for endometriosis. Cochrane Database Syst Rev. 2014;(4):CD011031. PMID: 24696265 DOI: 10.1002/14651858.CD011031.pub2

Dunselman GA, Vermeulen N, Becker C, Calhaz-Jorge C, D'Hooghe T, De Bie B, Heikinheimo O, Horne AW, Kiesel L, Nap A, Prentice A, Saridogan E, Soriano D, Nelen W; European Society of Human Reproduction and Embryology. ESHRE guideline: management of women with endometriosis. Hum Reprod. 2014;29:400-12. PMID: 24435778 DOI: $10.1093 /$ humrep/det457
Exacoustos C, Lariola I, Lazzeri L, De Felice G, Zupi E. Complications during pregnancy and delivery in women with untreated rectovaginal deep infiltrating endometriosis. Fertil Steril. 2016;106:1129-35.e1. PMID: 27445198 DOI: 10.1016/j.fertnstert.2016.06.024

Ferreira MC, Carneiro MM. Ultrasonographic aspects of endometriosis. J Endometr Pelvic Pain Disord. 2010;2:4754.

Ferrero S, Anserini P, Abbamonte LH, Ragni N, Camerini G, Remorgida V. Fertility after bowel resection for endometriosis. Fertil Steril. 2009;92:41-6. PMID: 18684451 DOI: $10.1016 /$ j.fertnstert.2008.04.070

Giudice LC, Kao LC. Endometriosis. Lancet. 2004;364:178999. PMID: 15541453 DOI: 10.1016/S0140-6736(04)17403-5

Guerriero $S$, Ajossa $S$, Minguez JA, Jurado $M$, Mais $V$, Melis GB, Alcazar JL. Accuracy of transvaginal ultrasound for diagnosis of deep endometriosis in uterosacral ligaments, rectovaginal septum, vagina and bladder: systematic review and meta-analysis. Ultrasound Obstet Gynecol. 2015;46:534-45. PMID: 26250349 DOI: $10.1002 /$ uog. 15667

Gupta S, Goldberg JM, Aziz N, Goldberg E, Krajcir N, Agarwal A. Pathogenic mechanisms in endometriosisassociated infertility. Fertil Steril. 2008;90:247-57. PMID: 18672121 DOI: $10.1016 /$ j.fertnstert.2008.02.093

Hart RJ, Hickey M, Maouris P, Buckett W. Excisional surgery versus ablative surgery for ovarian endometriomata. Cochrane Database Syst Rev. 2008;(2):CD004992. PMID: 18425908 DOI: $10.1002 / 14651858 . C D 004992$.pub3

Hudelist G, Ballard K, English J, Wright J, Banerjee $\mathrm{S}$, Mastoroudes $\mathrm{H}$, Thomas A, Singer CF, Keckstein J. Transvaginal sonography vs. clinical examination in the preoperative diagnosis of deep infiltrating endometriosis. Ultrasound Obstet Gynecol. 2011;37:480-7. PMID: 21433168 DOI: $10.1002 /$ uog. 8935

Jacques M, FreourT, Barriere P, Ploteau S. Adverse pregnancy and neo-natal outcomes after assisted reproductive treatment in patients with pelvic endometriosis: a casecontrol study. Reprod Biomed Online. 2016;32:626-34. PMID: 27068240 DOI: $10.1016 /$ j.rbmo.2016.03.005

Johnson NP, Hummelshoj L; World Endometriosis Society Montpellier Consortium. Consensus on current management of endometriosis. Hum Reprod. 2013;28:1552-68. PMID: 23528916 DOI: $10.1093 /$ humrep/det050

Koninckx PR, Meuleman C, Demeyere S, Lesaffre E, Cornillie FJ. Suggestive evidence that pelvic endometriosis is a progressive disease, whereas deeply infiltrating endometriosis is associated with pelvic pain. Fertil Steril. 1991;55:759-65. PMID: 2010001

Lafay Pillet MC, Huchon C, Santulli P, Borghese B, Chapron C, Fauconnier A. A clinical score can predict associated deep infiltrating endometriosis before surgery for an endometrioma. Hum Reprod. 2014;29:1666-76. PMID: 24903201 DOI: 10.1093/humrep/deu128 
Leone Roberti Maggiore U, Ferrero S, Mangili G, Bergamini $A$, Inversetti $A$, Giorgione $V$, Viganò $P$, Candiani $M$. A systematic review on endometriosis during pregnancy: diagnosis, misdiagnosis, complications and outcomes. Hum Reprod Update. 2016;22:70-103. PMID: 26450609 DOI: $10.1093 /$ humupd/dmv045

Matalliotakis IM, Cakmak H, Mahutte N, Fragouli Y, Arici A, Sakkas D. Women with advanced-stage endometriosis and previous surgery respond less well to gonadotropin stimulation, but have similar IVF implantation and delivery rates compared with women with tubal factor infertility. Fertil Steril. 2007;88:1568-72. PMID: 17349642 DOI: 10.1016/j.fertnstert.2007.01.037

Nisenblat V, Bossuyt PM, Farquhar C, Johnson N, Hull ML. Imaging modalities for the non-invasive diagnosis of endometriosis. Cochrane Database Syst Rev. 2016a;2:CD009591. PMID: 26919512 DOI: 10.1002/14651858.CD009591.pub2

Nisenblat V, Prentice L, Bossuyt PM, Farquhar C, Hull $M L$, Johnson $N$. Combination of the non-invasive tests for the diagnosis of endometriosis. Cochrane Database Syst Rev. 2016b;7:CD012281. PMID: 27405583 DOI: 10.1002/14651858.CD012281

Opøien HK, Fedorcsak P, Byholm T, Tanbo T. Complete surgical removal of minimal and mild endometriosis improves outcome of subsequent IVF/ICSI treatment. Reprod Biomed Online. 2011;23:389-95. PMID: 21764382 DOI: $10.1016 /$ j.rbmo.2011.06.002

Practice Committee of the American Society for Reproductive Medicine. Endometriosis and infertility: a committee opinion. Fertil Steril. 2012;98:591-8. PMID: 22704630 DOI: $10.1016 /$ j.fertnstert.2012.05.031

Reid S, Condous G. Update on the ultrasound diagnosis of deep pelvic endometriosis. Eur J Obstet Gynecol Reprod Biol. 2017;209:50-4. PMID: 27080442 DOI: $10.1016 /$ j.ejogrb.2016.02.040

Sallam HN, Garcia-Velasco JA, Dias S, Arici A. Long term pituitary down regulation before in vitro fertilization (IVF) for women with endometriosis. Cochrane Database Syst Rev. 2006;(1):CD004635. PMID: 16437491 DOI: 10.1002/14651858.CD004635.pub2

Somigliana $E$, Infantino $M$, Candiani $M$, Vignali $M$, Chiodini A, Busacca $M$, Vignali $M$. Association rate between deep peritoneal endometriosis and other forms of the disease: pathogenetic implications. Hum Reprod. 2004;19:168-71. PMID: 14688177 DOI: https://doi.org/10.1093/humrep/deg513
Somigliana E, Vercellini P, Daguati R, Giambattista E, Benaglia L, Fedele L. Effect of delaying post-operative conception after conservative surgery for endometriosis. Reprod Biomed Online. 2010;20:410-5. PMID: 20097135 DOI: $10.1016 /$ j.rbmo.2009.12.010

Somigliana E, Garcia-Velasco JA. Treatment of infertility associated with deep endometriosis: definition of therapeutic balances. Fertil Steril. 2015;104:764-70. PMID: 26342244 DOI: 10.1016/j.fertnstert.2015.08.003

Tosti C, Pinzauti S, Santulli P, Chapron C, Petraglia F. Pathogenetic Mechanisms of Deep Infiltrating Endometriosis. Reprod Sci. 2015;22:1053-9. PMID: 26169038 DOI: $10.1177 / 1933719115592713$

Vercellini P, Pietropaolo G, De Giorgi O, Daguati R, Pasin $R$, Crosignani PG. Reproductive performance in infertile women with rectovaginal endometriosis: is surgery worthwhile? Am J Obstet Gynecol. 2006;195:1303-10. PMID: 16707075 DOI: 10.1016/j.ajog.2006.03.068

Vercellini P, Somigliana E, Daguati R, Barbara G, Abbiati $A$, Fedele $L$. The second time around: reproductive performance after repetitive versus primary surgery for endometriosis. Fertil Steril. 2009;92:1253-5. PMID: 19476938 DOI: $10.1016 /$ j.fertnstert.2009.04.037

Vercellini $P$, Barbara G, Buggio L, Frattaruolo MP, Somigliana $E$, Fedele $L$. Effect of patient selection on estimate of reproductive success after surgery for rectovaginal endometriosis: literature review. Reprod Biomed Online. 2012;24:389-95. PMID: 22377155 DOI: $10.1016 /$ j.rbmo.2012.01.003

Vercellini P, Consonni D, Barbara G, Buggio L, Frattaruolo MP, Somigliana E. Adenomyosis and reproductive performance after surgery for rectovaginal and colorectal endometriosis: a systematic review and meta-analysis. Reprod Biomed Online. 2014;28:704-13. PMID: 24745831 DOI: $10.1016 /$ j.rbmo.2014.02.006

Vercellini P. Introduction: Management of endometriosis: moving toward a problem-oriented and patient-centered approach. Fertil Steril. 2015;104:761-3. PMID: 26363383 DOI: $10.1016 /$ j.fertnstert.2015.09.004

Vigano P, Corti L, Berlanda N. Beyond infertility: obstetrical and postpartum complications associated with endometriosis and adenomyosis. Fertil Steril. 2015;104:802-12. PMID: 26348274 DOI: $10.1016 /$ j.fertnstert.2015.08.030

Yang C, Geng Y, Li Y, Chen C, Gao Y. Impact of ovarian endometrioma on ovarian responsiveness and IVF: a systematic review and meta-analysis. Reprod Biomed Online. 2015;31:9-19. PMID: 25982092 DOI: $10.1016 /$ j.rbmo.2015.03.005 